\title{
REFLEXões ACERCA dA AÇÃo DOCENTE PARA O ENSINO DE LÍNGUA PORTUGUESA: TRANSPOSIÇÃo DIDÁTICA EM UMA AULA DE PONTUAÇÃo
}

\author{
REFLECTIONS ON THE TEACHING ACTION FOR THE TEACHING OF PORTUGUESE \\ LANGUAGE: DIDACTIC TRANSPOSITION IN A PUNCTUATION CLASS
}

REFLEXIONES ACERCA DE LA ACCIÓN DOCENTE PARA LA ENSEÑANZA DE LENGUA PORTUGUESA: TRANSPOSICIÓN DIDÁCTICA EN UNA CLASE DE PUNTUACIÓN

\section{Luan Tarlau Balieiro}

\section{(iD) 9}

Mestrando em Educação (UEM)

Discente do Programa de Pós-

Graduação em Educação

(PPE/UEM)

luan.tarlau@gmail.com

\section{Cindy Mayumi Okamoto \\ Luca \\ (iD) 9}

Mestranda em Educação (UEM)

Discente do Programa de Pós-

Graduação em Educação

(PPE/UEM)

lucacindy4@gmail.com

\section{Lilian Cristina Buzato \\ Ritter}

(iD) 9

Doutora em Estudos da Linguagem

(UEL)

Professora efetiva na Universidade

Estadual de Maringá (UEM)

Docente do Programa de Mestrado

Profissional em Letras

(PROFLETRAS-UEM)

lcbritter@uem.br

\begin{abstract}
Resumo
Neste artigo, partimos da problemática de o docente não suscitar reflexões quanto à maneira como ocorre o processo de transposição didática de um determinado conteúdo. Nosso objetivo central é discutir a prática docente nesse processo, focando-se no conteúdo de pontuação. Com respaldo nos pressupostos teóricos de Verret (1975) e Bakhtin (1992), metodologicamente, selecionamos uma aula ministrada a uma turma do $6^{\circ}$ ano do Ensino Fundamental de uma escola pública situada no noroeste do Paraná, para analisar, de modo específico, as adequações efetuadas no planejamento, além de compreender as características da transposição didática. Os resultados evidenciam a necessidade de fazer adaptações da teoria à prática, a considerar o contexto da turma, bem como o nível cognitivo dos estudantes. Concluímos que o saber científico requer ser moldado em um saber escolarizado por meio de estratégias que contribuam para o entendimento do conteúdo de forma mais eficaz e contextualizada.
\end{abstract}

Palavras-chave: Teoria. Prática. Ação docente. Transposição didática.

Recebido em: 24 de maio de 2021.

Aprovado em: 28 de setembro de 2021.

Como citar esse artigo (ABNT):

BALIEIRO, Luan Tarlau; LUCA, Cindy Mayumi Okamoto; RITTER, Lilian Cristina Buzato. Reflexões acerca da ação docente para o ensino de Língua Portuguesa: transposição didática em uma aula de pontuação. Revista Prática Docente, v. 6, n. 3, e078, 2021.

http://doi.org/10.23926/RPD.2021.v6.n3.e078.id1187 


\section{Abstract}

In this article, we start from the problem of the teacher not raising reflections on how the process of didactic transposition of a certain content occurs. Our main objective is to discuss the teaching practice in this process, focusing on the content of punctuation. Based on the theoretical assumptions of Verret (1975) and Bakhtin (1992), methodologically, we selected a class taught to a 6th grade elementary school of a public school located in the northwest of Paraná, to analyze, in a specific way, the adjustments made in the planning, besides understanding the characteristics of the didactic transposition. The results show the need to adapt theory to practice, considering the class context, as well as the students' cognitive level. We conclude that scientific knowledge requires to be shaped in an educated knowledge through strategies that contribute to the understanding of content in a more effective and contextualized way.

Keywords: Theory. Practice. Teaching action. Didactic transposition.

\section{Resumen}

En este artículo, partimos de la problemática de que el docente no suscite reflexiones sobre la manera como ocurre el proceso de transposición didáctica de un determinado contenido. Nuestro objetivo central es discutir la práctica docente en este proceso, centrándose en el contenido de puntuación. Con respaldo en los presupuestos teóricos de Verret (1975) y Bakhtin (1992), metodológicamente, seleccionamos una clase impartida a una clase del $6^{\circ}$ año de la Enseñanza Fundamental de una escuela pública situada en el noroeste de Paraná, para analizar, de modo específico, las adaptaciones efectuadas en la planificación, además de comprender las características de la transposición didáctica. Los resultados evidencian la necesidad de hacer adaptaciones de la teoría a la práctica, a considerar el contexto de la clase, así como el nivel cognitivo de los estudiantes. Concluimos que el saber científico requiere ser moldeado en un saber escolarizado por medio de estrategias que contribuyan para la comprensión del contenido de forma más eficaz y contextualizada.

Palabras clave: Teoría. Práctica. Acción docente. Transposición didáctica. 


\section{INTRODUÇÃo}

A atuação como professores na educação básica, em particular no Ensino Fundamental, permite-nos passar por experiências que ratifiquem as diferenças entre a teoria e a prática no momento de transpor didaticamente um determinado conteúdo. Pautando-nos no processo de transposição didática, notamos que o seu conceito é debatido por muitos estudiosos na literatura internacional e nacional, dentre eles, Verret (1975), o qual centrou a sua atenção na ação humana, ao objetivar a transformação dos saberes abstratos e teóricos em "ensináveis", considerando, sobretudo, a idade e os conhecimentos prévios de seus alunos.

Nesse mesmo contexto, Chevallard e Joshua (1991 apud ALMOULOUD, 2011) compreendem a transposição didática como um conjunto de mudanças pelas quais passa um saber dito "sábio", ou uma teoria, para que esse saber possa ser, de fato, ensinado. Assim, nas perspectivas de Verret (1975) e Chevallard e Joshua (1991 apud ALMOULOUD, 2011), entende-se o estudo da transposição didática como o fornecimento de explicações acerca do trajeto realizado pelo saber desde a sua elaboração científica até a sua chegada em sala de aula enquanto saber ensinado.

Alicerçados nas teorias apresentadas e nos centrando em uma abordagem qualitativa (GIL, 2002), estabelecemos, neste artigo, o objetivo central de discutir a prática docente no processo de transposição didática, focando-se no conteúdo de pontuação, de modo a contribuir com os debates sobre a formação inicial de professores de Língua Portuguesa. Partimos da problemática de o docente não suscitar reflexões quanto à maneira como ocorre esse processo acerca de um determinado conteúdo. Diante dessa problemática e considerando nosso objetivo central, demarcamos os seguintes objetivos específicos: i) compreender as características do processo de transposição didática; ii) analisar as adequações efetuadas no planejamento em uma aula com o conteúdo de pontuação para uma turma de $6^{\circ}$ ano do Ensino Fundamental.

O texto está estruturado em cinco seções, a contar com esta seção introdutória e com a seção destinada à apresentação das considerações finais. Antes de adentrarmos na análise de nossa ação docente, perpassamos, na segunda seção, por uma explicação concisa sobre as concepções de linguagem e a noção de transposição didática, para que haja uma compreensão mais exata acerca do ato de trespassar um saber científico em um saber escolarizado. Posteriormente à exposição dessas informações teóricas, descrevemos, na terceira seção, um episódio ocorrido conosco na turma já referida e proveniente de uma escola pública localizada no noroeste do Paraná, analisando-o. Na quarta seção, apresentamos as nossas reflexões acerca 
da experiência. A princípio, é pertinente mencionar que esse episódio se refere a uma circunstância de nossa transposição didática acerca de saberes disciplinares fundamentais para o ensino de Língua Portuguesa, especificamente os saberes gramaticais, no caso, a pontuação. Esta constitui o objeto-alvo da didatização deste texto por acreditarmos ser um conteúdo suscetível a realizar um trabalho interativo em situação de ensino e aprendizagem, a partir do uso de piadas, conforme veremos adiante.

\section{AS CONCEPÇÕES DE LINGUAGEM E A NOÇÃO DE TRANSPOSIÇÃo DIDÁTICA}

Ao adotarmos a definição de língua proposta pelo filósofo e pensador russo Bakhtin (1992) enquanto um fenômeno social da interação verbal efetuada por meio de um enunciado, observamos que a linguagem é engendrada em uma perspectiva social e histórica, ideológica e dialógica, focalizando o perfil de aluno postulado no documento oficial intitulado "Base Nacional Comum Curricular" (BRASIL, 2018). Logo, em um contexto de ensino e aprendizagem, é atribuível ao docente a incumbência de pensar a língua como um fenômeno constitutivo e dialógico nos termos bakhtinianos, já que, como processo histórico, a língua mantém estreitas relações com a sociedade, a ideologia, as circunstâncias políticas e a dimensão cultural, estando presente no próprio cotidiano do educando, não ensinada de maneira segmentada, tampouco descontextualizada. Tal noção dialógica da linguagem passa a ser um dos objetos de investigação de muitas pesquisas no âmbito dos estudos linguísticos, em razão de sua harmonização com os encaminhamentos das políticas públicas e das abordagens de ensino.

Considerar a noção dialógica da linguagem é, pois, considerar uma concepção de linguagem como forma de interação, desenvolvida no Círculo de Bakhtin, a qual defende, notoriamente, que o cerne da linguagem é a interação discursiva. Tal concepção se difere de outras duas: a linguagem como expressão do pensamento e como instrumento de comunicação. Nesse caso, em uma perspectiva dialógica, a língua não é: a) entendida como uma concepção de linguagem que prevê a tradução ou a exteriorização de um pensamento (TRAVAGLIA, 1997), calcada no ideário de que quem fala ou escreve bem, seguindo e dominando as normas que compõem a gramática da língua, é um indivíduo que sistematiza logicamente o seu pensamento; b) entendida como uma concepção de linguagem alicerçada a uma Teoria da Comunicação que compreende a língua como um instrumento de conversação para transmitir informações (GERALDI, 1997), com o postulado basilar de que é um sistema organizado por sinais e signos, que serve como meio de comunicabilidade entre os indivíduos a partir de um 
código, ou seja, de um conjunto de signos combinados por meio de regras em que o emissor é conduzido a transmitir uma certa mensagem ao receptor.

A língua, em uma perspectiva dialógica, objetiva realizar ações, agir sobre o outro e atuar no âmago das interações sociais nas quais se insere e engendra o contexto de produção do enunciado, isto é, a situação comunicativa, a relação interpessoal - formal/informal - que se estabelece entre os interlocutores, abrangendo aquilo que se diz, a quem, como se diz, em que situações tudo isso se efetiva e a valoração axiológica que permeia e constitui qualquer enunciado.

Com base nas asserções teóricas referentes às três concepções de linguagem - expressão do pensamento, instrumento de comunicação e forma de interação -, elucidadas brevemente nos parágrafos anteriores, julgamos pertinente afirmar que compete ao professor de língua materna adotar uma concepção de linguagem que atenda aos requisitos de formação do alunado, em consonância com a proposta educacional vigente que manifesta uma dimensão dialógica da língua, compreendida como um sistema linguístico social em sua interação com os fatores culturais, históricos e ideológicos. Ao adotar uma concepção de linguagem coerente com uma proposta que revele uma dimensão dialógica da língua, o professor tem a tarefa de planejar suas aulas teoricamente para, em momento posterior, colocá-las em prática, ou seja, transpor didaticamente os conteúdos propostos em seu plano.

Desse modo, para compreender a noção de transposição didática, determinamos ser importante explorar a sua terminologia. Empregado pela primeira vez por Michel Verret, sociólogo francês, em sua tese de doutorado intitulada "Le temps des études", desenvolvida no ano de 1975, o termo transposição didática foi bastante esmiuçado por esse pesquisador. Em sua tese, Verret realizou um estudo sociológico ao enfocar a distribuição do tempo das atividades escolares, isto é, o tempo regulado pelo próprio objeto de estudo e o tempo da didática. Para o estudioso, a didática é a transmissão de um saber adquirido, ou seja, é a transmissão dos indivíduos que sabem para os indivíduos que ainda não sabem, daqueles indivíduos que aprenderam para aqueles indivíduos que aprendem (VERRET, 1975). Assim, a transposição, no ideário de Verret (1975), aponta para as transformações que um determinado saber sofre por ocasião de sua exposição didática. Com isso, destaca-se que a prática didática também se desdobra em duas: na prática do saber e na prática da transmissão desse saber. 


\subsection{A TRANSPOSIÇÃO NO PROCESSO DE ENSINO E APRENDIZAGEM}

O professor português Nóvoa (2012) explana que os educadores desenvolvem as suas identidades pelas referências aos saberes teóricos e práticos a que são expostos e pela anuência aos valores com que se identificam. Por isso, é imprescindível entender quais são esses saberes e quais são essas referências, visto que são esses saberes e referências que os educadores fomentam para desempenhar os seus trabalhos.

Sobre as categorias da base de conhecimentos para o educador, Peres e Greco (2014) mencionam o psicólogo educacional norte-americano Shulman (1987), afirmando que, se tais categorias fossem organizadas, elas deveriam, ao menos, abarcar:

- conhecimento do conteúdo;

- conhecimento pedagógico geral, especialmente dos princípios amplos e da estratégia de direção e de organização da sala de aula, os quais parecem ultrapassar o assunto conteudístico;

- conhecimento do currículo, com particular compreensão dos materiais e dos programas que servem como "ferramentas de ofício" para os professores;

- conhecimento do conteúdo pedagógico: aquele amálgama especial de conteúdo específico e pedagogia, ligado somente à função do professor, a sua própria forma de conhecimento profissional;

- conhecimento de alunos e suas características;

- conhecimento do contexto educacional, abrangendo desde os trabalhos do grupo da sala de aula até a administração das escolas, as características gerais e culturais das comunidades;

- conhecimento dos fins educacionais, propostas, valores, filosofia e fundamentos históricos (SHULMAN, 1987 apud PERES; GRECO, 2014, p. 174-175).

Peres e Greco (2014) destacam dois tipos de conhecimentos inscritos nos estudos de Shulman (1987). O primeiro é o "conhecimento do conteúdo", que se refere aos "saberes disciplinares" adquiridos pelos professores no âmbito de sua formação, seja inicial, seja continuada. Esses saberes se atrelam aos diversos campos do conhecimento (história, geografia, literatura, línguas etc.) e são dispostos na forma de disciplinas. Situam-se no âmbito do saber acumulado pela humanidade ao longo do tempo, “[...] categorizado pela Epistemologia como conhecimentos científicos estruturados sob a forma de conceitos, conteúdos e proposições" (PERES; GRECO, 2014, p. 175).

O segundo é o "conhecimento do conteúdo pedagógico", que pode ser associado ao que o didata matemático francês Chevallard (2005) nomeia de "transposição didática", conforme expõem Peres e Greco (2014). As autoras ainda salientam que, ao discutir o conceito de transposição didática, o estudioso examina que o sistema didático é formado por três elementos: o professor, o saber escolarizado e o aluno. Para que esse sistema se realize, Chevallard (2005) 
orienta que esses três elementos precisam atender a algumas condições determinadas pela prática pedagógica. Peres e Greco (2014) explicam que Chevallard (2005), em suas reflexões, parte das condições estipuladas ao elemento "saber escolarizado" e preconiza a "teoria da transposição didática" ou "processo de transposição didática", cuja essência está na transformação do elemento saber para que ele possa ser, por certo, ensinado. As estudiosas escrevem:

Vale ressaltar que o processo de transformação (está imbricado no conceito de "transposição didática" - esse destaque é pertinente para que o termo "transposição didática" não seja reduzido a uma ação pedagógica em que o professor "pega" um saber científico de um determinado lugar (das teorias, dos livros etc.) e o "transporte" para outro lugar (a cabeça do aluno, no caso) (PERES; GRECO, 2014, p. 176).

Adiante, as autoras aclaram que a concepção do saber disciplinar enquanto conhecimento categorizado, arquitetado a partir do método científico, ao contemplar a estruturação, as proposições e as teorias, contribuiu para que fosse desenvolvida, ao longo do tempo, a imagem do professor como um indivíduo transmissor de múltiplos conteúdos. No caso do professor de Língua Portuguesa, enquanto um indivíduo transmissor de gramática normativa descontextualizada. Sobre essa questão, Peres e Greco (2014) mencionam o pesquisador e pedagogo Mazzeu (1998), o qual analisa o fato de que, para que os alunos se apropriem do saber escolar e se tornem autônomos e críticos, o docente tem a necessidade de se apropriar desse saber e se tornar, também, cada vez mais autônomo e crítico. Portanto, sem essa autonomia e sem essa criticidade, compreendemos ser inviável que o docente efetue, de forma dinâmica e contextualizada, a transposição didática de conteúdos gramaticais de Língua Portuguesa.

Ao explorarmos o conceito de transposição didática nas seções iniciais deste artigo, compreendendo, de maneira global, a sua significação, é pertinente refletirmos sobre um problema que muito ocorre em sala de aula e está intimamente relacionado com a noção de transposição didática. Tal conflito é destacado pela estudiosa Ritter (2012), que afirma o fato de que o problema eminente da transposição didática é o momento em que o docente considera a proposta didática que lhe é apresentada como algo já finalizado, alheia a reflexões, adequações e indagações. A estudiosa pondera que o professor, ao considerar a proposta didática como algo já acabado, sem a necessidade de refletir sobre o conteúdo ali apresentado, age, notoriamente, de forma passiva, além de se encaminhar para o paradigma da instrução a ser seguida, estando restrito àquilo. Para a pesquisadora, "o professor não se vê mais como responsável pelas suas 
ações, assumindo o papel de transmissor de conteúdos, no mais das vezes, que ainda lhes são desconhecidos" (RITTER, 2012, p. 63-64).

A fim de atribuir um novo significado ao conceito de transposição didática, considerando essa nova significação algo imprescindível, o professor e pesquisador francês Halté (2008), ao refletir sobre o ensino e a aprendizagem de línguas, propõe a noção de elaboração didática, que surge em substituição à noção de transposição didática, relacionada à aplicação de conhecimentos científicos em um movimento de transpor o conhecimento científico para o conhecimento a ser ensinado em sala de aula. Halté (2008) assinala que, ao pensar na elaboração didática dos saberes para o ensino de línguas, tenciona-se, especialmente, a edificação de competências linguísticas.

É exatamente a serviço dessas competências linguísticas que os conhecimentos são ensinados. Ademais, os conteúdos ensinados não se limitam a conhecimentos científicos transpostos, visto que, para o estudioso, tais conteúdos refratam as "práticas sociais de referência", isto é, os usos sociais efetivos que se faz da língua no contexto das distintas interações que ocorrem nas diferentes esferas da atividade humana. A concepção de elaboração didática remete a uma didática praxiológica em que a construção do conhecimento é entendida como processo e é resultado da opção por uma metodologia que considera a participação do professor e do aluno no processo didático.

Peres e Greco (2014) evocam a nossa atenção para o fato de que Shulman (1987), ao abordar a transformação de conteúdo - saber científico - em produto de ensino - saber escolarizado -, averigua a necessidade de os docentes compreenderem o conteúdo que, de fato, ensinam. As autoras enfatizam que o professor deve usar a sua base de conhecimentos para prover as suas escolhas e ações. No que concerne a essa situação, Peres e Greco (2014) também mencionam que Shulman (1987) verifica que a meta da formação do professor “[...] não é doutriná-lo ou treiná-lo para se comportar de modos prescritos, mas educá-lo para pensar, raciocinar profundamente sobre o seu ensino e desempenhá-lo de forma consciente" (PERES; GRECO, 2014, p. 178).

Todas as considerações tecidas por Shulman (1987) e exploradas por Peres e Greco (2014) abrangem o que o psicólogo educacional norte-americano nomeia de processo do raciocínio e da ação pedagógica, ou seja, um processo que contempla um ciclo de atividades de compreensão, de transformação, de instrução, de avaliação e de reflexão. A seguir, essas atividades são descritas numericamente. 
1. Compreensão: na visão de Shulman (1987), a atividade de compreensão tange ao fato de que ensinar é primeiro entender. Assim, antes de ensinar, o professor precisa compreender criticamente o que ensinará, ou seja, espera-se que ele entenda o que ensina e, se possível, que o entenda de maneiras variadas (PERES; GRECO, 2014).

2. Transformação: acerca dessa atividade, Shulman (1987) pondera, sucintamente, que os conteúdos a serem ensinados devem ser transformados de alguma maneira, a fim de motivar o aprendizado dos alunos.

3. Instrução: nessa atividade, o estudioso afirma que ela envolve o desempenho observável da variedade do ato de ensinar e inclui três aspectos primordiais à pedagogia, a saber: i) a organização e administração da sala de aula; ii) a discussão do conteúdo; iii) o ato de tecer explicações claras, com a apresentação de descrições vividas, nomeando e conferindo trabalhos, ao interagir efetivamente com os alunos, por meio de perguntas e de sondagens das respostas, das reações, dos elogios e das críticas.

4. Avaliação: Shulman (1987) afirma que a avaliação se refere à verificação da compreensão dos alunos no processo pedagógico. Conforme destacam Peres e Greco (2014), o autor também postula que tal atividade é dirigida ao próprio ensino do professor, às lições e aos materiais empregados em suas tarefas.

5. Reflexão: nessa atividade, o estudioso elucida que o professor "olha" para o seu ensino e observa como ele ocorreu, reconstruindo, reordenando e/ou recapturando os eventos, as emoções e as realizações. É como se fosse um processo pelo qual um profissional aprende pela experiência (PERES; GRECO, 2014).

\subsection{DO SABER CIENTÍFICO PARA O SABER ESCOLARIZADO}

Para Mello (2012), a necessidade de se ensinar o conhecimento conduz à necessidade de modificá-lo. Essa modificação é justamente entendida como sendo a transposição didática. A pesquisadora atesta que, ao "[...] entrarem para a escola, os objetos de conhecimento - o saber científico ou as práticas sociais - convertem-se em "objetos de ensino", isto é, em conteúdo curricular" (MELLO, 2012, p. 1). Assim, é “[...] preciso modificar o saber científico para que este se transforme em objeto de ensino "ensinável", isto é, em condições de ser aprendido pelo aluno" (MELLO, 2012, p. 1). Na acepção da autora, o docente realiza a modificação do saber científico em saber "ensinável” de forma constante, porém adverte que nem sempre realiza essa modificação eficazmente. 
Com o objetivo de contribuir com todas as discussões a respeito da ação de transpor didaticamente um conteúdo, a seguir, apresentamos, de modo sistematizado, um quadro com informações acerca de como a transposição didática ocorre.

Quadro 1 - As ações para se transpor didaticamente um conteúdo

Ação 1: o conteúdo tem de ser selecionado ou recortado de acordo com o que o professor considera relevante para constituir as competências consensuadas na proposta pedagógica.

Ação 2: o professor precisa ter em mente o fato de que alguns aspectos ou temas devem ser mais enfatizados, reforçados ou diminuídos.

Ação 3: o conhecimento deve ser dividido para facilitar a sua compreensão, para, posteriormente, o professor voltar a estabelecer a relação entre aquilo que foi dividido.

Ação 4: o professor deve distribuir o conteúdo no tempo para organizar uma sequência, um ordenamento, uma série linear ou não linear de conceitos e relações.

Ação 5: o professor precisa determinar uma forma de organizar e apresentar os conteúdos, como por meio de textos, gráficos, dentre outros recursos.

Fonte: Adaptado de Mello (2012).

Destarte, o processo de transposição didática expõe o fato de que a disciplina escolar não é o conhecimento científico, mas uma parte dele, além de modificada (MELLO, 2012). Todavia, é mais do que o saber científico, pois também abrange os procedimentos para o seu ensino. Realizar a transposição didática acarreta algumas competências, o que exige o direcionamento da nossa atenção para desenvolvê-las, sendo válido afirmar que tais competências devem estar abarcadas no plano de educação continuado da escola, da região ou do sistema de ensino.

Para compreender, de maneira mais sistematizada, quais são essas competências, a seguir, destacamos um segundo quadro, com a exposição de informações arroladas sobre as competências referidas.

Quadro 2 - Competências para se realizar a transposição didática

Competência 1. Saber fazer recortes na sua área de especialidade de acordo com um julgamento sobre relevância, pertinência e significância para o desenvolvimento das competências escolhidas que garantirão a inserção do aluno no mundo moderno.

Competência 2. Saber selecionar quais aspectos daquele conhecimento são, de fato, importantes.

Competência 3. Dominar o conhecimento em questão, de maneira articulada e harmônica, incluindo o modo característico e específico pelo qual esse conhecimento é engendrado.

Competência 4. Saber relacionar o conhecimento em questão com os de outras áreas, isto é, desenvolver uma interdisciplinaridade, uma intercomunicação efetiva com as demais disciplinas que possuem relação com a disciplina a qual o professor é responsável por ensinar.

Competência 5. Saber como contextualizar esse conhecimento.

Competência 6. Ter um pressuposto ou uma "aposta" sobre como o estudante arquiteta esse conhecimento e como deveria conhecer.

Competência 7. Dominar estratégias de ensino eficazes para sistematizar circunstâncias de aprendizagem que efetivamente promovam no estudante as competências que se quer, por certo, desenvolver, aflorar.

Fonte: Adaptado de Mello (2012). 
Diante do exposto, Araujo (2014) se respalda nos pressupostos teóricos do estudioso francês Chatel (1995), que destaca a informação de que o saber preparado, para ser efetivamente ensinado, não pode mais se identificar pura e simplesmente com o saber "sábio", ao possibilitar, assim, livrarmo-nos do problema de origem e referência. Segundo o que nos reporta Araujo (2014), o foco dos estudos de Chatel (1995) se guia para a questão da transmissão dos saberes na escola, uma questão essencialmente atrelada às aprendizagens. Nessa perspectiva, transformar os saberes preceituados nos programas efetivos de ensino não é uma ação ímpar do docente: é, pois, uma ação dos docentes em interação com os seus alunos. Sobre a postura do professor, Araujo (2014) se centra nos dizeres de Chatel (1995):

O que os professores fazem quando ensinam depende necessariamente dos alunos, de uma forma ou de outra. Ensinar não é somente preparar uma aula para tal ou tal turma cujos hábitos e características conhecemos; é também gerir, na aula, o envolvimento imediato dos alunos com os conteúdos do saber ensinado (CHATEL, 1995 apud ARAUJO, 2014, p. 244).

Assim, Araujo (2014) nos expõe que Chatel visa a compreender melhor de que modo a atividade do saber se efetiva em sala de aula, isto é, em contexto de ensino e aprendizagem. Podemos concluir que se trata de compreendermos como os professores, no seu modo de ensinar, asseguram tangivelmente a relação dos alunos com os conteúdos a serem ministrados. É propriamente nos pautando nessa questão que relataremos e analisaremos, na seção seguinte, a nossa ação docente em uma turma de $6^{\circ}$ ano do Ensino Fundamental.

\section{A ATUAÇ̃̃o no $6^{\circ}$ ANO do EnSINo Fundamental: DESCRIÇÃo dos PROCEDIMENTOS METODOLÓGICOS DA AULA MINISTRADA}

Nossa experiência foi em uma turma de $6^{\circ}$ ano do Ensino Fundamental de uma escola pública localizada no noroeste do Paraná. O conteúdo ministrado da aula que selecionamos para discussão foi a pontuação, tendo em vista que se trata de um conteúdo que deve ser trabalhado pelo professor de Língua Portuguesa e, sobretudo, na etapa em questão, é demasiado complexo, pois abrange não apenas questões morfológicas e sintáticas, mas também a articulação entre esses elementos e um certo nível de interpretação do discente, a fim de que se possa aplicar a pontuação adequada, sem alteração de sentido do texto. Portanto, muitas vezes, esse fato pode ser um obstáculo para que haja a transposição desse conteúdo de maneira efetiva.

Diante disso, acreditamos ser fundamental tecer reflexões sobre a nossa prática durante a execução de aulas relacionadas à pontuação, para que, enquanto pesquisadores e docentes, possamos, a partir da ação, observá-la, questioná-la e ampliá-la, o que está em consonância com 
os pressupostos de Gil (2002, p. 90) em relação às pesquisas de abordagem qualitativa, as quais traçam um paralelo entre a vivência e a reflexão, a fim de que "a ordenação lógica do trabalho torne-se significativamente mais complexa". Por intermédio de nossa experiência, esperamos contribuir com novas pesquisas e suscitar formas didáticas que trabalhem a pontuação no Ensino Fundamental de maneira potencializadora, considerando a integralidade dos educandos.

Assim, elaboramos um plano de aula que contemplasse o conteúdo referido e que, consequentemente, minimizasse o uso incorreto e/ou a ausência da pontuação nos textos redigidos pelos discentes. Ao ter em vista o fato de que os alunos são muito novos e para não tornar o trabalho algo fastidioso e de difícil compreensão, buscamos utilizar, como respaldo para a abordagem do assunto, piadas. Enfatizamos que as piadas escolhidas eram de fácil entendimento e não levavam consigo temas pejorativos ou, até mesmo, aqueles que fossem considerados "avançados demais" para a faixa etária dos alunos. O quadro a seguir apresenta algumas das piadas entregues à turma.

Quadro 3 - Algumas piadas entregues para a realização do trabalho acerca da pontuação

Piada 1:

Joãozinho pergunta para a sua mãe:

— Mãe, você sabia que o vermelho é a cor do amor?

- Sei sim. Por quê?

— Te amo! Tome aqui o meu boletim!

Piada 2:

A professora pergunta aos alunos:

— Se eu for à feira e comer 4 peras, 3 bananas, 10 laranjas e 1 melancia, qual será o resultado?

Do fundo da sala, Joãozinho grita:

— Uma dor de barriga!

Piada 3:

Ao ver o boletim do neto com muitas notas vermelhas, o avô resolve lhe dar um tremendo de um sermão:

- No meu tempo, Juquinha, eu era o melhor aluno em História. Só tirava nota dez...

— Tudo bem, avô, mas tem um detalhe! - Disse o neto.

— Que detalhe, Juquinha?

- No seu tempo, havia uns sessenta anos a menos de história para estudar, né?!

Fonte: Produzido pelos autores, a partir do plano de aula aplicado.

Feita a seleção das piadas que seriam trabalhadas, visamos a propiciar uma reflexão no alunado sobre as consequências que o uso incorreto, ou até mesmo a ausência da pontuação, ocasiona no sentido das piadas. Não buscamos aprofundar ainda mais o trabalho, elevando-o a um nível sintático, tendo em vista a faixa etária que os alunos se encontravam. 
Dessa forma, iniciamos a aula perguntando aos alunos se eles gostam de piadas, a fim de aproximá-los do objeto escolhido para a realização do trabalho com a pontuação. Questionados, solicitamos a narração de algumas piadas que eles conheçam e gostem; depois, interrogamos se essas piadas foram lidas ou ouvidas por eles. Esse último questionamento tem o objetivo de explicitar o fato de que as pausas ou os momentos de entonação, que são evidentes na piada ouvida, são demonstrados, na escrita, por intermédio de diversos pontos, os quais possuem determinadas funções.

Dada a explicação, entregamos uma piada recortada para cada aluno, pedimos para que todos lessem o texto que está em mãos e, por fim, que o contasse ao colega do lado. Ao término da contação, indagamos os alunos sobre os motivos pelos quais se pode considerar aquilo que eles contaram inicialmente e/ou acabaram de ler como piada(s); tal abordagem visa a explicitar o fato de que a pontuação é um fator primordial para a caracterização do texto lido como uma piada. Para uma maior exemplificação, nós os questionamos se a retirada da pontuação da(s) piada(s) lida(s)/contada(s) ocasionaria alguma mudança no sentido e, consequentemente, na produção do riso. Aguardamos pelas respostas e, assim que as obtivemos, lemos algumas piadas que foram entregues a eles, mas, agora, sem pontuação alguma, e solicitamos aos discentes que eles também lessem, de maneira entonacional, as outras piadas que lhes foram entregues, mas como se elas estivessem sem pontuação. Por fim, propiciamos uma reflexão acerca das consequências da ausência da pontuação nas piadas lidas.

Mediante o respaldo voltado aos efeitos que a ausência da pontuação proporciona em um texto, perguntamos aos discentes quais são os pontos que eles conheciam, redigimo-los no quadro e pedimos para que os copiassem. Feita a transcrição, suscitamos uma reflexão sobre: quais seriam os motivos pelos quais existem tais pontos que eles disseram anteriormente; quais seriam as suas funções; e como seria uma oração/período sem eles. Finalizada a reflexão, elencamos todos os aspectos explanados pelos discentes no quadro e pedimos para que eles os copiassem. Assim que os alunos terminaram as suas cópias, embasamos as respostas dadas por eles, ao explicarmos, de maneira mais concisa, a finalidade de cada ponto.

Ao partir da ideia de que os alunos já teriam internalizado as funções dos pontos, entregamos uma folha que continha piadas, as quais não tinham pontuação ou que apresentassem um uso equivocado, principalmente no que concerne ao uso da vírgula, e solicitamos que os alunos realizassem uma leitura silenciosa delas. O quadro a seguir apresenta o exercício proposto. 
Quadro 4 - Exercício proposto para adequação coletiva da pontuação em piadas

A PONTUAÇÃO ADEQUADA NO AUXÍLIO PARA O SENTIDO DA PIADA
Leia as piadas a seguir:
1. O irmão e a irmã entram em casa machucados A mãe ficou preocupada e quis saber o que tinha
acontecido A irmã disse É porque eu escorreguei em uma casca de banana e caí A mãe perguntou E você
meu filho como se machucou Eu ri do tombo dela
2. Dizia a professora Para termos uma vida saudável devemos nos alimentar de forma correta Por
isso é importante sabermos o valor nutritivo dos alimentos Paulinha dê um exemplo de alimento que
engorda Pão professora respondeu Paulinha Exatamente enfatizou a professora Pão é um dos alimentos
que mais engorda Errado professora gritou o aluno lá do fundo O pão não engorda e sim quem o come
3. - Manhêe?
— O que é. Meu filho!
— Lá na escola os meus coleguinhas estão dizendo que eu sou o maior mentiroso?
- Larga de, bobagem garoto você não está, na escola ainda.
4. O Garotinho todo contente estudando num, livro de geografia se vira para, a mãe e exclama!
- Pronto mãe? Já, sei tudo sobre geografia se não acredita é só perguntar?
Feliz da vida com aquela situação. A mãe não perde tempo e pergunta:
— Muito bem onde está, localizada a Inglaterra!
— Na página 52? - respondeu prontamente o pequeno.

Fonte: Produzido pelos autores, a partir do plano de aula aplicado.

Findada a leitura, suscitamos uma reflexão com os alunos se a ausência da pontuação ou o uso equivocado dela proporcionou, nas piadas lidas, uma mudança no sentido e/ou se gerou algum tipo de desconforto no momento da leitura de tais. Além disso, propiciamos o seguinte questionamento: quais poderiam ser os pontos mais utilizados nas piadas que estão sem pontuação, para que, assim, elas tivessem um sentido mais concreto?

Depois, pedimos para que os estudantes observassem as piadas que estavam com a pontuação inadequada. Após a observação, pontuamos corretamente, de maneira interacional, algumas. Para tanto, lemos a piada assim como ela estava e, depois, questionamos o que/onde estava causando estranhamento ou problema na compreensão da piada; feito isso, indagamos aos alunos como eles poderiam solucionar esse problema, sobre qual ponto melhor se encaixaria no local em questão e que daria o suporte necessário para a compreensão e correção sintática da piada.

Terminado o nosso auxílio coletivo, solicitamos que os educandos pontuassem individualmente as outras piadas que precisavam ser pontuadas e seriam apresentadas em outro exercício. O quadro a seguir evidencia o exercício proposto. 
Quadro 5 - Exercício proposto para adequação individual da pontuação em piadas

\section{AGORA É A SUA VEZ!}

As piadas a seguir estão com a pontuação inadequada ou até mesmo sem ponto algum. Vamos consertar?

1. Numa aula de Boas Maneiras a professora argumentava com seus alunos Joãozinho suponha que somos convidados para almoçar na casa de um amigo Acabado o almoço o que devemos dizer Diz o menino Cadê a sobremesa

2. Para ensinar ao filho o valor do dinheiro e tentar diminuir algumas de suas compras inúteis? A mãe o fez, escrever uma relação detalhada de como gastava a mesada! Um dia em que escrevia com muito esforço as suas contas ele disse?

— Sabe mamãe! Desde que, comecei a anotar tudo o que gasto sempre penso bem antes de comprar alguma coisa?

A mãe, ficou toda contente pelo êxito do seu método e ele completou!

- Eu nunca compro nada que seja difícil de escrever

3. Um garotinho foi à mercearia e perguntou Quanto custam os ovos Cinco reais respondeu o vendedor E se eu devolver as cascas

4. O telefone toca e um garotinho atende do outro lado Trata-se do médico de família desejando falar com o pai da criança Como este não se encontra em casa naquele momento o médico pede para que lhe anote um recado Espere um pouco que vou pegar um lápis para escrever diz o menino Passados alguns instantes ele retorna e diz Espere um pouco eu peguei um lápis com a ponta quebrada Vou pegar outro Passados mais alguns instantes ele retorna e diz Pronto já peguei um lápis com ponta Mas o senhor sabe de uma coisa Eu ainda não sei escrever

Fonte: Produzido pelos autores, a partir do plano de aula aplicado.

Por fim, ficamos circulando em sala, a fim de sanar quaisquer tipos de dúvidas que os alunos pudessem ter.

\section{A TRANSPOSIÇÃo DIDÁtica do CONTEÚdo: DISCUSSÕES REFLEXIVAS ACERCA DA EXPERIÊNCIA}

Quando planejamos algo, temos em mente que barreiras e situações inesperadas podem acontecer, as quais, consequentemente, levarão a uma mudança do que havia sido esperado; da mesma forma aconteceu com o nosso plano de aula. Inicialmente, havíamos pensado em propor uma reflexão nos alunos sobre a importância de se utilizar os pontos, ao ter em vista que são eles quem demarcam uma expressão, um questionamento, uma pausa e, como consequência disso, auxiliam na construção do sentido para um texto. A decisão por restringir a abordagem do conteúdo a algo que seja apenas reflexivo se deu em detrimento do nível escolar que os alunos do $6^{\circ}$ ano se encontram: não têm um aprofundamento sintático para a abordagem de temas, por exemplo, predicado, verbo transitivo e intransitivo, os quais se fazem necessários para explicarmos onde é permitido ou não colocar determinados pontos. 
Entretanto, no momento em que tivemos de transpor e propiciar tal reflexão, percebemos que não seria fácil. Isso aconteceu, já que os alunos, em muitos casos, pontuavam as piadas sem embasamento algum, apenas porque acreditavam que naquele espaço entre as duas palavras seria interessante acrescentar algum ponto, não importava qual fosse. Em muitos casos, tivemos de realizar, a partir do plano de aula, uma leitura entonacional repetitiva das piadas para que eles percebessem se faria sentido ou não inserir um ponto no local em que eles acreditavam ser o ideal, o que os auxiliou muito na compreensão acerca da utilização adequada da pontuação.

Ademais, em consequência do fato de que os alunos são crianças e que, com isso, o seu entendimento requer um pouco mais de trabalho, em muitos casos, apenas as perguntas contidas no plano de aula não eram suficientes para que houvesse o entendimento sobre o conteúdo em questão. Como exemplificação acerca da teoria e da transposição que realizamos, podemos utilizar o momento em que questionamos os alunos sobre a função de cada ponto - "Por qual motivo vocês acreditam que exista o ponto? E a vírgula? E o ponto de exclamação? E o ponto de interrogação? E os dois pontos? E o travessão?’. Nessa circunstância, tivemos de adaptar as perguntas propostas no plano de aula para serem feitas oralmente da seguinte forma: "Para marcar o fim de uma frase, qual é o ponto que vocês usam? Quando vocês querem separar ou deslocar alguma palavrinha ou frase, para dar uma pausa, qual ponto vocês usam? E para dar uma entonação e perguntar algo, quais são os pontos que vocês usam? E quando vocês vão apresentar uma informação que virá em seguida? Qual é o ponto a ser usado? E para introduzir uma fala, que ponto vocês usam?". Ponderamos que essas adaptações se reportam ao postulado de Verret (1975): é preciso objetivar a transformação dos saberes abstratos e teóricos em “ensináveis", de modo a contemplar a idade e os conhecimentos prévios de nossos alunos.

Nesse ínterim, as contribuições de Verret (1975) são muito frutíferas para que possamos moldar nossa didática no momento de elaborar o plano de aula e, sequencialmente, na sua aplicação. Quanto à transposição didática do conteúdo de pontuação, é comum nos depararmos com episódios em que apenas se expõe a função de cada ponto e um exemplo de sua aplicação; a nosso ver, não observamos, nessa ocasião, um exercício contextualizado - ou, como bem elucida Verret (1975), um saber que seja, por certo, ministrado de maneira situacional e que abarque a capacidade intelectiva de cada educando. Ao inserir no planejamento o trabalho com piadas, pudemos notar o quão contextualizada se tornou a transposição, já que os estudantes de 
nível fundamental têm o conhecimento desse tipo de texto e, mais eficazmente, podem verificar a aplicabilidade de cada ponto, dadas as suas características.

Logo, o conteúdo de pontuação, em sua forma abstrata e teórica, quando potencializado em algo que seja ensinado, conforme vimos na adaptação do planejamento da aula, oportuniza aos alunos: empregar os sinais de pontuação em distintas circunstâncias; ampliar o vocabulário e as possibilidades de escrita mediante a estrutura discursiva de textos diversos - no episódio em foco, os estudantes podem, além de compreender o funcionamento dos sinais de pontuação, adquirir saberes quanto às especificidades que comportam uma piada; ler com compreensão; e desencadear posturas de interação, de colaboração e de troca de experiências em grupos, já que a atividade pode ser, sem dúvidas, realizada coletivamente.

Com base no exposto, foi perceptível que o plano poderia ter sido elaborado de maneira mais simplória para que se pudesse proporcionar uma compreensão exata do conteúdo. Foi evidente que, se nós não pensássemos sobre como os alunos estavam retendo a transposição em questão e, assim, não adaptássemos o nosso plano de aula, a internalização da utilização correta da pontuação seria muito baixa, tendo em vista apenas o uso de palavras que eles não possuem um contato mais frequente.

Importa-nos abordar um aspecto: Bakhtin (1992) alude que a interação discursiva compõe a essência da linguagem. No contexto escolar, inúmeras atividades sociais são observadas, dentre elas, a interação entre alunos e professores na execução de múltiplas tarefas. Conforme os postulados do Círculo de Bakhtin, o interlocutor - real ou presumido - não equivale a um sujeito passivo. Ao perceber e compreender o significado linguístico de um discurso, ele ocupa concomitantemente em relação ao locutor uma ativa posição responsiva, com o intuito de ocasionar uma construção social da consciência e da linguagem pelo que entendemos como intersubjetividade, uma condição da vida social que confere o compartilhamento de sentidos, experiências e conhecimentos entre sujeitos. No papel de locutores referente à exposição do conteúdo de pontuação, com as adequações realizadas, pudemos compreender os alunos - os interlocutores de nossa aula - como sujeitos ativos e aptos a internalizarem conhecimentos de modo efetivamente situacional e interativo.

Dessa maneira, com a adequação na abordagem de determinados questionamentos esperados pelo plano de aula e partindo da acepção de que o cerne da linguagem é a interação discursiva (BAKHTIN, 1992), os alunos compreenderam o intuito da aula em discussão. Tal constatação pode ser evidenciada no momento em que pedimos para que eles realizassem os 
exercícios propostos, sejam os coletivos, sejam os individuais, no qual os discentes, ao perceberem a ideia que precisavam expor, sabiam qual ponto era o mais adequado para aquela determinada situação, provando-nos que houve um cumprimento do objetivo de nossa aula.

\section{AlguMAS INFORMAÇÕES CONCLUSIVAS}

Indubitavelmente, a busca do docente por utilizar métodos que auxiliem ou, até mesmo, diferenciem a abordagem do conteúdo expresso no plano de aula é essencial. Os resultados de nossa prática evidenciam o quão necessário é verificar quando não está sendo viável o modo pelo qual seguimos a explicação de um determinado conteúdo e de transformá-la em algo mais próximo da realidade dos estudantes. Além disso, as adaptações variarão em torno do contexto da turma e do nível cognitivo dos alunos integrantes dela.

Portanto, as adequações são necessárias, uma vez que objetivam propiciar uma maior internalização do que está sendo trabalhado, sem lacunas ou dubiedades que possam surtir efeitos maiores no futuro. Assim, o docente, mediante a sondagem do nível escolar e do perfil da turma, deve, antecipadamente, refletir sobre o conteúdo para realizar alterações no plano de aula, adequando-o à turma, a fim de cumprir com um dos papéis da ação docente: proporcionar a compreensão de um determinado conteúdo, de forma contextualizada, a todos os alunos. Afinal, o saber científico requer ser moldado em um saber escolarizado por meio de estratégias que contribuam eficazmente para o entendimento do conteúdo.

\section{REFERÊNCIAS}

ALMOULOUD, Saddo Ag. As transformações do saber científico ao saber ensinado. Educar em Revista, Curitiba, v. 1, número especial, p. 191-210, 2011.

ARAUJO, Paula Francineti Ribeiro de. Ensino de Língua Portuguesa: a transposição didática em questão. Eutomia, Recife, v. 14, n. 1, p. 240-262, 2014.

BAKHTIN, Mikhail. Marxismo e filosofia da linguagem. São Paulo: Hucitec, 1992.

BRASIL. Ministério da Educação. Base Nacional Comum Curricular: Educação é a base. Educação Infantil, Ensino Fundamental e Ensino Médio. Brasília, DF: MEC, 2018. Disponível em: http://basenacionalcomum.mec.gov.br/images/BNCC_EI_EF_110518_versaofinal_site.pdf. Acesso em: 30 abr. 2021.

CHATEL, Elisabeth. Marchés et prix: savoirs enseignés et façons d'enseigner en Sciences Économiques et Sociales. Paris: INRP, 1995.

CHEVALLARD, Yves; JOHSUA, Marie-Alberte. La transposition didactique. Grenoble: La Pensée Sauvage-Éditions, 1991. 
CHEVALLARD, Yves. La transposición didáctica: del saber sábio al saber enseñado. Buenos Aires: Aique Grupo Editor, 2005.

GERALDI, João Wanderley. Portos de passagem. 4. ed. São Paulo: Martins Fontes, 1997.

GIL, Antonio Carlos. Como elaborar projetos de pesquisa. 4. ed. São Paulo: Atlas, 2002.

HALTÉ, Jean-François. O espaço didático e a transposição. Fórum Linguístico,

Florianópolis, v. 5, n. 2, p. 117-139, 2008.

MAZZEU, Francisco José Carvalho. Uma proposta metodológica para a formação continuada de professores na perspectiva histórico-social. Cadernos CEDES, Campinas, v. 19, n. 44, p. 59-72, 1998.

MELLO, Guiomar Namo de. Transposição Didática, Interdisciplinaridade e

Contextualização. 2012. Disponível em: https://docplayer.com.br/12476931-Transposicaodidatica-interdisciplinaridade-e-contextualizacao-guiomar-namo-de-mello.html. Acesso em: 30 abr. 2021.

NÓVOA, Antonio. Diz-me como ensinas, dir-te-ei quem és. In: FAZENDA, Ivani Catarina Arantes. (org.). A pesquisa em educação e as transformações do conhecimento. 12. ed. Campinas: Papirus, 2012. p. 29-41.

PERES, Aparecida Fatima; GRECO, Eliana Alves. Transposição didática no processo de formação inicial de professores de Língua Portuguesa: o lugar dos saberes disciplinares. Entretextos, Londrina, v. 14, n. 1, p. 172-189, 2014.

RITTER, Lilian Cristina Buzato. Práticas de leitura/análise linguística com crônicas no ensino médio: proposta de elaboração didática. 2012. $242 \mathrm{f}$. Tese (Doutorado em Estudos da Linguagem) - Universidade Estadual de Londrina, Londrina, 2012.

SHULMAN, Lee S. Knowledge and teaching: foundations of the New Reform. Harvard Educational Review, [S. I.], v. 57, n. 1, p. 1-22, 1987.

TRAVAGLIA, Luiz Carlos. Gramática e Interação: uma proposta para o ensino de gramática no $1^{\circ}$ e $2^{\circ}$ graus. São Paulo: Cortez, 1997.

VERRET, Michel. Le temps des études. Paris: Honoré Champion, 1975. 